This is an electronic reprint of the original article. This reprint may differ from the original in pagination and typographic detail.

Author(s): Haapanen, Mika; Tervo, Hannu

Title: $\quad$ Cumulative inertia or cumulative stress? Migration behaviour of Finnish graduates

Year: $\quad 2009$

Version:

Please cite the original version:

Haapanen, M., \& Tervo, H. (2009). Cumulative inertia or cumulative stress? Migration behaviour of Finnish graduates. Migration letters, 6(1), 83-90.

https://doi.org/10.33182/ml.v6i1.88

All material supplied via JYX is protected by copyright and other intellectual property rights, and duplication or sale of all or part of any of the repository collections is not permitted, except that material may be duplicated by you for your research use or educational purposes in electronic or print form. You must obtain permission for any other use. Electronic or print copies may not be offered, whether for sale or otherwise to anyone who is not an authorised user. 


\title{
Cumulative inertia or cumulative stress? Migration behaviour of Finnish graduates
}

\author{
Mika Haapanen \& Hannu Tervo* \\ School of Business and Economics, University of Jyväskylä
}

\begin{abstract}
An interesting yet largely unstudied question regarding labour migration behaviour and residence duration is whether migration becomes more or less likely over time. This paper analyses the determinants of residence duration for Finnish graduates. Our results affirm the importance of cumulative inertia as a determinant of migration. The longer a person stays in a region, the smaller are the hazard rates of migration. However, for those graduates who moved to a new region during their year of graduation, the propensity for repeat migration is particularly high during their first three years of residence.
\end{abstract}

Keywords: Labour migration, graduates, residence duration, repeat migration

\footnotetext{
* School of Business and Economics, P.O. Box 35, FI-40014 University of Jyväskylä, Finland. Emails: mphaapan@econ.jyu.fi \& htervo@econ.jyu.fi
} 


\section{Introduction}

Within the migration literature, two competing hypotheses have been proposed (Huff and Clark, 1978; Molho, 1995; Gordon and Molho, 1995). First, the hypothesis of 'cumulative inertia' posits that the propensity to move should fall gradually over time. The longer an individual stays at a certain place, the less likely she is to move (Fischer, 1999). An individual's attachments to home, friends, and area of residence grow over the course of a residence spell, since their social networks develop and local human capital accumulates. An alternative 'cumulative stress' hypothesis argues that migration become more likely over time, because individuals become increasingly dissatisfied with their situation in the current location as time passes, perhaps reflecting a progression through their life-cycle or career.

Recent studies on long-distance migration have reported evidence in support of the cumulative inertia hypothesis (Détang-Dessendre and Molho, 1999, 2000). The aim of this paper is to study the migration behaviour and duration of residence spells after obtaining an educational degree in Finland. Understanding the migration decisions of graduating students is important, as they represent a very mobile group of individuals. Yet, surprisingly few studies have considered migration patterns from school to employment (however, see Faggian et al., 2006, 2007) or the duration of residence spells after full-time education (see, however, Bailey, 1993; Détang-Dessendre and Molho, 1999, 2000). In this paper we investigate the length of residence spells of recent graduates. We explore whether the effect of residence duration on migration behaviour is negative or positive. In other words, is cumulative inertia or cumulative stress dominant?

\section{Data and methods}

Our analysis is based on a Longitudinal Census File and a Longitudinal Employment Statistics File constructed by Statistics Finland. These two register-based datasets, together with data drawn from some other registers, provide panel data from 1987 to 2002 for each resident of Finland. From this combined data a 7 percent random sample was taken for this study. The longitudinal data allow us to observe changes in the place of residence as well as in the length of residence spells in new locations. These data are 
very rich, enabling us to study the impact of a variety of personal, household, labourmarket and regional characteristics on the duration of residence spells.

Individuals less than 35 years old who graduated from their first secondary or tertiary education institution in 1987-2001 were selected for analysis. Their residence spells were followed up to the first interregional move (or until 2002, the censoring year). That is, a move from one region to another is terminating an observed residence spell. This results in a sample of 47,937 residence spells, each from a different individual. The maximum possible observed duration of right-censored residence spells is fifteen years. This is a longer period than that in previous studies (Bailey, 1993; Détang-Dessendre and Molho, 1999, 2000).

Finland consists of 79 regions (or nineteen provinces; the Åland Islands are excluded), and each region has several municipalities. Before 1994, students were registered in their home municipality even if they had moved to pursue their studies. Legislation changed in 1994, after which students could also register in the municipality of their educational institution. Thus, for some students, their place of residence is potentially incorrect in our data. This recording problem is reduced by the fact that most students, especially those enrolled in secondary education, study in their home region. Had we studied migration between municipalities, the problem would have been more severe. In addition, the location information is correct after graduation, because students have entered the labour market by that point. We do, however, check the sensitivity of our results to the change of legislation in 1994.

Descriptive analysis shows that a significant proportion of the 47,937 graduates $(12.4 \%)$ had already moved during their graduation year (henceforth referred to as "graduationyear movers"). After the change in the legislation in 1994, they consisted of both return and onward migrants, while before 1994, they mainly consisted of onward migrants. In both cases, this recent migration experience is likely to increase the propensity to move after graduation year (DaVanzo, 1983; Bailey, 1993). Thus, the above-mentioned recording problem may also influence the migration rates of the graduation-year movers and stayers differently.

To analyse the migration process, life-table estimates of residence survival rates and hazard rates of migration are calculated. The hazard rate is defined as the probability 
that a move will occur in the current year, given that no movement has occurred up to the beginning of that year. The survival rate indicates the probability of staying in the current region until time $t$ after graduating from full-time education. In addition, a discrete-time model of residence duration is specified and estimated. In the estimation, a flexible, semi-parametric specification of the baseline hazard is adopted. This allows us to study the role of duration dependence in the migration decisions of graduates after controlling all other factors that are assumed to affect the decisions. These factors include personal and household characteristics, labour-market experience, and regionspecific factors as well as an unobserved heterogeneity term. In this letter, we do not, however, present the model specification and estimation results (Haapanen and Tervo, 2007) but only utilise the estimates and sample values to predict hazard and survival rates that are needed for an analysis of duration dependence.

\section{Life-table estimates}

Table 1 presents life-table estimates of residence survival rates and hazard rates of migration by migration status during the year of graduation. The hazard rate of migration in the first year after graduation is close to 9 percent for those who did not move during the year of graduation. The hazard rates decrease significantly as residence spells grow longer, falling to only 1 percent during the last interval. The hazard rates are much higher for graduation-year movers. During the first years of a residence spell, the hazard rates, however, drop faster for the movers. Nevertheless, these rates remain higher during later time intervals than the hazard rates of those who did not move during the year of graduation. These descriptive results suggest that there is greater cumulative inertia than cumulative stress in the residence decisions of recent Finnish graduates.

A comparison of the estimated survival functions indicates a statistical difference between the graduation-year movers and stayers. The observed level of significance for the Log-rank test is less than 0.001, leading us to reject the null hypothesis that the survival functions do not differ. A comparison of the median residence durations (that is, survival time) also shows considerable differences. An estimate of the median duration of a residence spell is seven years for graduation-year movers. This means that half of those who moved during their graduation year will move again within seven years. The corresponding figure for graduation-year stayers is over 15 years. 
Table 1 Life-table estimates of residence duration by migration status during the year of graduation

\begin{tabular}{ccccccc}
\hline \hline \multirow{2}{*}{$\begin{array}{c}\text { Interval } \\
\text { (years) }\end{array}$} & \multicolumn{3}{c}{ Graduation-year stayers } & \multicolumn{3}{c}{ Graduation-year movers } \\
\cline { 2 - 7 } & $\begin{array}{c}\text { Number of } \\
\text { obs. }\end{array}$ & $\begin{array}{c}\text { Hazard } \\
\text { rate, } \%\end{array}$ & $\begin{array}{c}\text { Survival } \\
\text { rate, } \%\end{array}$ & $\begin{array}{c}\text { Number of } \\
\text { obs. }\end{array}$ & $\begin{array}{c}\text { Hazard } \\
\text { rate, } \%\end{array}$ & $\begin{array}{c}\text { Survival } \\
\text { rate, } \%\end{array}$ \\
\hline 1 & 41977 & 8.87 & 91.13 & 5960 & 17.63 & 82.37 \\
2 & 35840 & 6.44 & 85.26 & 4541 & 13.21 & 71.48 \\
3 & 31344 & 5.22 & 80.81 & 3639 & 11.35 & 63.37 \\
4 & 27599 & 4.73 & 76.99 & 2942 & 8.36 & 58.07 \\
5 & 24234 & 4.44 & 73.57 & 2473 & 7.08 & 53.96 \\
6 & 21211 & 3.97 & 70.64 & 2087 & 4.94 & 51.30 \\
7 & 18398 & 3.05 & 68.49 & 1815 & 5.29 & 48.59 \\
8 & 15809 & 2.88 & 66.52 & 1563 & 3.26 & 47.00 \\
9 & 13452 & 2.42 & 64.91 & 1372 & 3.57 & 45.32 \\
10 & 11159 & 2.22 & 63.47 & 1179 & 2.63 & 44.13 \\
11 & 9114 & 1.83 & 62.31 & 1004 & 2.19 & 43.16 \\
12 & 7172 & 1.23 & 61.54 & 807 & 2.73 & 41.99 \\
13 & 5261 & 1.14 & 60.84 & 584 & 2.05 & 41.12 \\
14 & 3489 & 1.09 & 60.18 & 398 & 1.26 & 40.61 \\
15 & 1778 & 0.67 & 59.77 & 196 & 2.55 & 39.57 \\
\hline \hline
\end{tabular}

Notes: Estimated median of residence duration is 7 (over 15) years for movers (stayers). Log-rank test for the equality of the survivor functions: $\chi^{2}=1313.8$ with d.f. $=1$ ( $\mathrm{p}$-value $<0.001$ ).

\section{Model-based estimates}

The preceding descriptive analysis suggests that the hazard rates of migration decrease substantially with increases in residence duration. Our econometric model allows us to investigate whether this result still holds after the effects of other factors have been controlled (Haapanen and Tervo, 2007). To control for the change in legislation concerning residence registration, year dummies are included in the model. Moreover, a random individual effect is likely to affect unobserved heterogeneity. In addition, we tried two dummy variables (one for graduation-year movers and one for stayers) that separated those students who graduated before the change in legislation in 1994 from those who graduated later, but these variables were not significant and thus dropped from the final specification. The pattern of duration dependence remained unchanged when the model was estimated only for students graduating from 1994 onwards.

As we would expect, once the explanatory variables are added to the model and statistically significant unobserved heterogeneity is controlled, negative duration dependence weakens (Van den Berg, 2001). That is, the hazard rate of migration decreases less over the course of the residence spell than suggested by the descriptive 
statistics. For graduate-year stayers, the hazard rate drops by $68.7 \%$ over 15 years, whereas Table 1 predicts a drop of about $92 \%$.

To illustrate the changes in the hazard rates of migration over the course of a residence spell, we predicted hazard rates for a typical graduate using our duration model. As can be seen in Figure 1, the hazard rates are much higher for a graduation-year mover who is considering whether to migrate again. This demonstrates the importance of recent migration experience on migration propensity. Note that the difference between the hazard functions is not proportional. For example, during the first five years of residence, a graduation-year mover has, on average, a 2.7 times greater probability of migration, whereas this hazard ratio is only 2.1 during subsequent intervals.

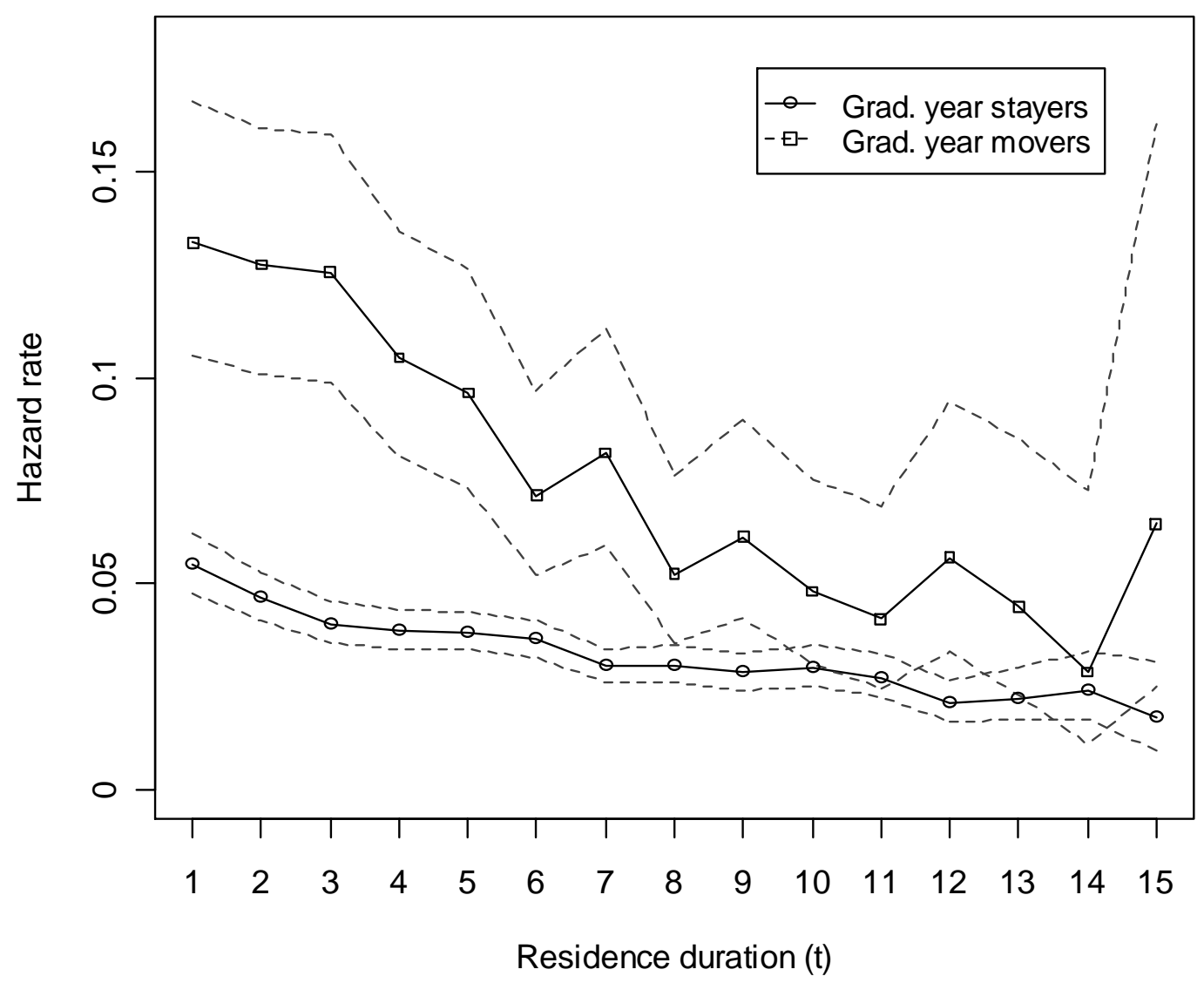

Figure 1 Predicted hazard rates of migration with $95 \%$ confidence intervals

Differences in duration dependence also emerge between the graduation-year movers and stayers. For a graduation-year stayer, negative duration dependence in the hazard rates of migration can be seen throughout the residence spell; the longer a graduationyear stayer continues living in her region, the smaller are the hazard rates. For example, 
the migration rate in the first year of the spell is estimated at 0.055 , whereas it is only 0.027 when $t=11$. The hazard rate falls by half in ten years. Thus, we found clear evidence in support of cumulative inertia for those who did not move during their graduation year.

The conclusions for the graduation-year mover are less precise due to a smaller number of observations. Figure 1 demonstrates, nevertheless, that in the first few years of residence in a new location, the hazard rate of re-migration tends to fall slowly. Thereafter, the fall in the hazard rates intensifies substantially. Cumulative inertia starts to dominate cumulative stress. In fact, we found no statistically significant difference between these two types of graduates in the last few time intervals.

Finally, Figure 2 shows the corresponding predicted survival probabilities for each residence duration. The probability that a graduate will stay in her region of origin for one year after graduation is 0.95 if she did not move during the graduation year and 0.87 if she moved. Similarly, the probability of staying in a region for five years is 0.80 for a graduation-year stayer considering first-time migration, whereas this probability is as low as 0.54 for a graduation-year mover who is considering repeat migration.

\section{Conclusion}

We found evidence in support of cumulative inertia in the residence decisions of graduates in Finland. That is, the longer a person stays in a region, the smaller are the hazard rates of migration. However, the hazard rates are much higher for those who have already moved during their graduation year as compared to those who have not yet moved. In addition, for graduation-year movers, the propensity for repeat migration is particularly high during the first three years of their residence spell. Therefore, our results suggest that a policy aiming to avert or encourage interregional migration is likely to be most effective if targeted at this group of new residents.

Acknowledgements. This study is supported by the Academy of Finland (project numbers 120185 and 127049). 


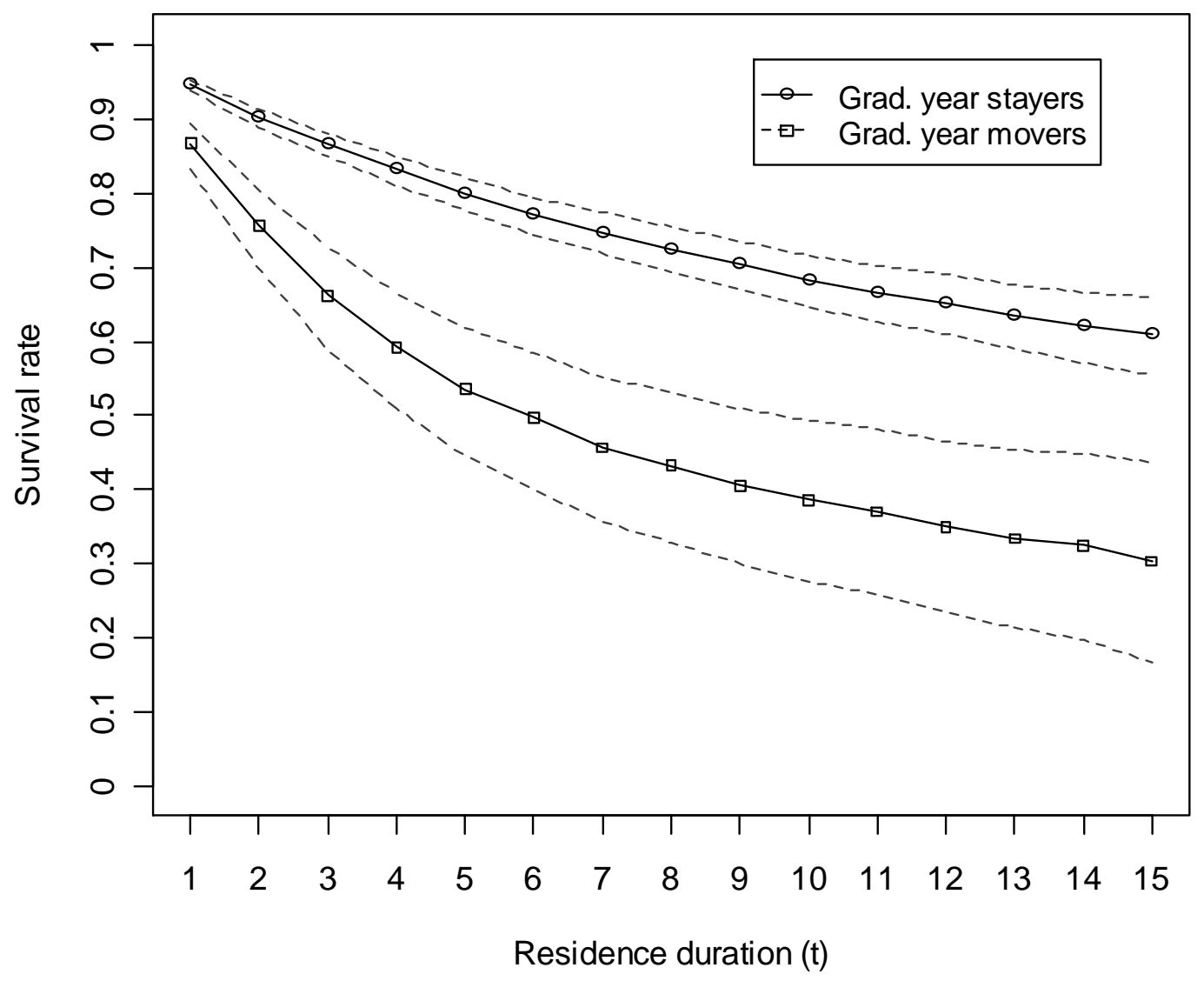

Figure 2 Predicted survival rates with $95 \%$ confidence intervals. 


\section{References}

Bailey, A. J., 1993, "Migration history, migration behaviour and selectivity", Annals of Regional Science, 27: 315-326.

DaVanzo, J., 1983, "Repeat migration in the United States: who moves back and who moves on?" Review of Economics and Statistics, 65: 552-559.

Détang-Dessendre, C. and I. Molho, 1999, "Migration and changing employment status: a hazard function analysis", Journal of Regional Science, 39(1): 103-123.

Détang-Dessendre, C. and I. Molho, 2000, "Residence spells and migration: a comparison for men and women”, Urban Studies, 37(2): 247-260.

Faggian, A., P. McCann and S. Sheppard, 2006, “An analysis of ethnic differences in UK graduate migration behaviour", Annals of Regional Science, 40(2): 461-471.

Faggian, A., P. McCann and S. Sheppard, 2007, "Some evidence that women are more mobile than men: gender differences in U.K. graduate migration behaviour", Journal of Regional Science, 47(3): 517-539.

Fischer, P. A., 1999, On the Economics of Immobility - Regional Development and Migration in the Age of Globalisation, Verlag Paul Haupt, Bern, Stuttgart, Wien.

Gordon, I. R. and I. Molho, 1995, "Duration dependence in migration behaviour: cumulative inertia versus stochastic change", Environment and Planning A, 27: 961-975.

Haapanen, M. and H. Tervo, 2007, Migration behaviour and duration of residence spells after education, University of Jyväskylä, School of Business and Economics, Working Paper 340, Jyväskylä.

Huff, J. O. and W. A. Clark, 1978, "Cumulative stress and cumulative inertia: a behavioral model of the decision to move", Environment and Planning A, 10: 11011119.

Molho, I., 1995, "Migrant inertia, accessibility and local unemployment", Economica, 62: $123-132$.

Van den Berg, G. J., 2001, "Duration models: specification, identification, and multiple durations", in: Heckman, J. and E. Leamer (eds.) Handbook of Econometrics, Volume V, North-Holland, Amsterdam, Chapter 55, pp. 3381-3460. 